Correction

\title{
Correction: Overexpression of AKR1C3 significantly enhances human prostate cancer cells resistance to radiation
}

\author{
Shao-Qian Sun ${ }^{1, *}$, Xiaobin Gu${ }^{1, *}$, Xian-Shu Gao ${ }^{1}, \mathbf{Y i ~ L i}^{2}$, Hongliang $\mathbf{Y u}^{3}$, Wei Xiong ${ }^{4}$, \\ Hao Yu ${ }^{1}$, Wen Wang ${ }^{1}$, Yingbo $\mathrm{Li}^{2}$, Yingqi Teng ${ }^{5}$, Demin Zhou ${ }^{2}$ \\ ${ }^{1}$ Department of Radiation Oncology, Peking University First Hospital, Peking University, Beijing, China \\ ${ }^{2}$ State Key Laboratory of Natural and Biomimetic Drugs, School of Pharmaceutical Sciences, Peking University, Beijing, China \\ ${ }^{3}$ Department of Radiation Oncology, Jiangsu Cancer Hospital Affiliated with Nanjing Medical University, Nanjing, China \\ ${ }^{4}$ Tangshan People's Hospital, Hebei, China \\ ${ }^{5}$ Beijing Reciproca Pharmaceutical Co. Ltd., Beijing, China \\ *These authors contributed equally to this work
}

Published: April 28, 2020

Copyright: Sun et al. This is an open-access article distributed under the terms of the Creative Commons Attribution License 3.0 (CC BY 3.0), which permits unrestricted use, distribution, and reproduction in any medium, provided the original author and source are credited.

This article has been corrected: In Figure $2 \mathrm{C}$, in the column labeled ' $4 \mathrm{GY}$ ', the picture of Indocin- is mistakenly identical to the picture for Indocin+. The corrected Figure 2C, obtained using original data, is shown below. The authors declare that these corrections do not change the results or conclusions of this paper.

Original article: Oncotarget. 2016; 7:48050-48058. https://doi.org/10.18632/oncotarget.10347

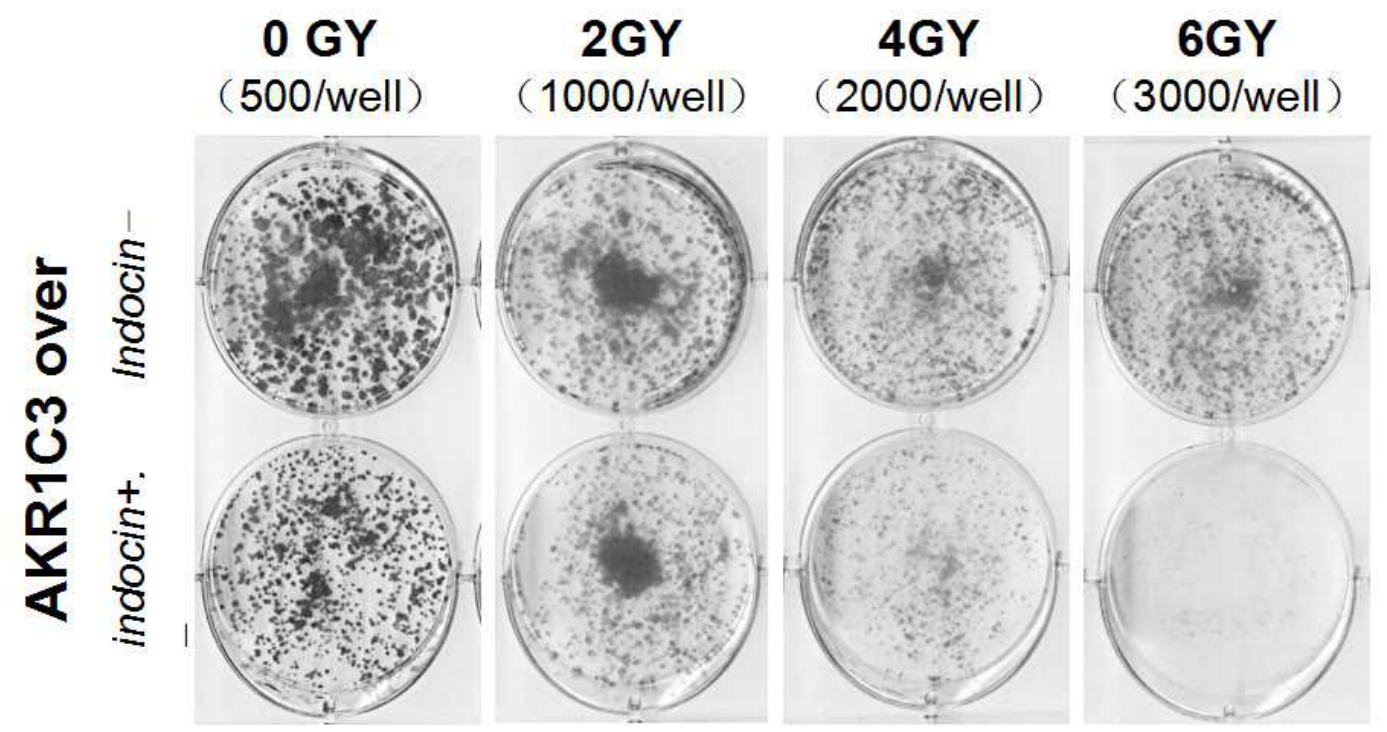

Figure 2: Indomethacin, an inhibitor of AKR1C3 activity, overcomes radiation resistance. (A) AKR1C3-over cells and control cells were treated with or without $20 \mathrm{mmol} /$ indomethacin for 2 days, and western blotting was performed; (B, C) AKR1C3-over cells and Control cells were treated with or without $20 \mathrm{mmol} /$ indomethacin for 2 days, and clonogenic assay was performed; (D) Colony forming efficiency were calculated and results are presented as means SD of two experiments performed in duplicate. 